\title{
O COMPARTILHAMENTO DE INFRAESTRUTURAS DE REDE NO SEAC E NO SETOR DE TELECOMUNICAÇÕES
}

Mauricio Soares Urti ${ }^{1}$

\section{RESUMO:}

O artigo se propõe a realizar um diagnóstico de diferença identificada na estrutura dos setores de telecomunicações e de prestação de serviços de televisão por assinatura, designados como os Serviços de Acesso Condicionado, notadamente com relação às estruturas de rede que os assistem. O diagnóstico considera a formação, evolução e os desafios impostos aos setores estudados, de modo que inspirado na doutrina das essential facilities, aponta a alternativa do compartilhamento de infraestruturas de redes e meios de rede como um caminho para os prestadores de serviços desses segmentos de mercado, recentemente pressionados a revisitarem os seus modelos de negócios.

Palavras-Chave: Diagnóstico. Setores de Telecomunicações. SEAC. Compartilhamento de redes. Essential facilities.

\section{THE SHARING OF NETWORK INFRASTRUCTURES IN THE PAY-TV AND TELECOMMUNICATIONS SECTORS}

\begin{abstract}
:
The article intends to diagnose a difference between the structures of the telecommunications and the pay-TV broadcasting sectors, named as the Serviços de Acesso Condicionado, with regards to the network structures which assist both sectors. The diagnose considers the formation, evolution from both sectors as well as the challenges imposed to them. Inspired by the essential facilities doctrine, the study points the sharing of networks and the sharing of network's infrastructure as an alternative for the providers from these markets under analysis, specially due to the fact that they ve been recently pressured to revisit their business models.
\end{abstract}

KEYWORDS: Diagnoses. Telecommunications. Pay-Tv. Sharing of Networks. Essential facilities.

\section{INTRODUÇÃO}

O artigo se propõe a realizar um diagnóstico de diferença existente entre as estruturas de negócio adotadas por prestadores de serviços de televisão por assinatura, designados como

\footnotetext{
${ }^{1}$ Mestrando em Direito da Regulação pela Escola de Direito do Rio de Janeiro da Fundação Getulio Vargas (FGV Direito Rio). Pós-Graduado em Direito Empresarial, com concentração em Direito Processual Civil, Societário e Mercado de Capitais, pela FGV Direito Rio, Brasil. Graduado em Direito pela Universidade do Estado do Rio de Janeiro. mauricio.urti@fgv.edu.br
} 
os Serviços de Acesso Condicionado ("SeAC") ${ }^{2}$, notadamente as sociedades responsáveis pela distribuição do conteúdo audiovisual ofertado na televisão por assinatura, e pelos prestadores de serviços de telecomunicações, para fins deste estudo neles encerrados tanto os Serviços de Telefonia Fixo Comutados ("STFC") ${ }^{3}$, como os Serviços de Comunicação Multimídia ("SCM") ${ }^{4}$, e os Serviços Móvel Pessoal ("SMP") ${ }^{5}$, prestados por sociedades operadoras de serviços de telecomunicações.

$\mathrm{O}$ estudo se debruça sobre uma diferença existente entre esses dois setores, notadamente a adoção de modelos de compartilhamento pelos seus atores, ressalvado que em se tratando do SeAC, este modelo de compartilhamento, tanto de infraestruturas de rede quanto de meio de rede, não é corriqueiramente adotado, enquanto em se tratando dos setor de telecomunicações, as concessionárias ou autorizadas de STFC, SMP, e/ou SCM, mais recentemente apontam para a adoção de modelos de negócio que consagram o compartilhamento de infraestruturas de suas redes, ou meios de rede.

Destaque-se que muito embora tanto o SeAC quanto o setor de telecomunicações se estruturem em modelos de rede, as sociedades prestadoras de serviços do SeAC não fizeram uso de soluções de compartilhamento de infraestruturas, enquanto mais recentemente, no Brasil, algumas prestadoras de serviços de telecomunicações se valeram de acordos com vistas à implementação de soluções de compartilhamento de suas redes, bem como de elementos dessas redes.

$\mathrm{O}$ artigo indicará algumas peculiaridades de cada qual dos dois setores analisados, quais sejam o SeAC e o setor das telecomunicações, tanto por meio da contextualização de suas origens, desenvolvimentos, além dos seus marcos regulatórios, i.e., a Lei $\mathrm{n}^{\circ}$. 12.485, de

\footnotetext{
${ }^{2}$ Resolução no 581 da ANATEL, de 26 de março de 2012. "Art. 4. O SeAC é o serviço de telecomunicações de interesse coletivo, prestado no regime privado, cuja recepção é condicionada à contratação remunerada por assinantes e destinado à distribuição de conteúdos audiovisuais na forma de pacotes, de canais de programação nas modalidades avulsa de programação e avulsa de conteúdo programado e de Canais de Programação de Distribuição Obrigatória, por meio de tecnologias, processos, meios eletrônicos e protocolos de comunicação quaisquer."

${ }^{3}$ Resolução no 477 da ANATEL, de 07 de agosto de 2007. "Art. $3^{\circ}$. (...) XXVI - Serviço Telefônico Fixo Comutado - STFC: serviço de telecomunicações que, por meio de transmissão de voz e de outros sinais, destinase à comunicação entre pontos fixos determinados, utilizando processos de telefonia".

${ }^{4}$ Resolução $\mathrm{n}^{\circ} 614$ da ANATEL, de 28 de maio de 2013. "Art. $3^{\circ}$. O SCM é um serviço fixo de telecomunicações de interesse coletivo, prestado em âmbito nacional e internacional, no regime privado, que possibilita a oferta de capacidade de transmissão, emissão e recepção de informações multimídia, permitindo inclusive o provimento de conexão à internet, utilizando quaisquer meios, a Assinantes dentro de uma Área de Prestação de Serviço."

${ }^{5}$ Resolução no 477 da ANATEL, de 07 de agosto de 2007. “Art. 4 Serviço Móvel Pessoal - SMP é o serviço de telecomunicações móvel terrestre de interesse coletivo que possibilita a comunicação entre Estações Móveis e de Estações Móveis para outras estações, observado o disposto neste Regulamento".
} 
12 de setembro de 2011 (a "Lei do SeAC") e a Lei n". 9.472, de 11 de julho de 1997 (a “LGT"), além da movimentação das agências incumbidas das suas regulações, quais sejam a Agência Nacional do Cinema (“Ancine”) e a Agência Nacional de Telecomunicações (“Anatel”).

O estudo também procurará identificar algumas peculiaridades de cada qual das atividades econômicas desenvolvidas nos setores em análise, com vistas a traçar um diagnóstico de possíveis razões para que as soluções de compartilhamento de infraestrutura tenham encontrado espaço no setor das telecomunicações, enquanto não tenham sido identificadas no SeAC.

Inspirado em instituto emprestado da doutrina estrangeira, notadamente a chamada doutrina das essential facilities, o artigo também identificará a alternativa utilizada por parte de prestadores de serviços de telecomunicações, no Brasil, em adotarem soluções de compartilhamento de suas infraestruturas de rede, além de meios de rede, estes essenciais à prestação dos serviços a que se propõem.

Por fim, ainda que reconhecidamente tímido o emprego de soluções de compartilhamento por parte de prestadoras de serviços de telecomunicações, o estudo proporá o uso de soluções de compartilhamento às prestadoras de serviços do SeAC, especialmente diante dos desafios iminentes a serem enfrentados por ambos os setores analisados, seja em decorrência do advento do ingresso de sociedades provedoras de conteúdo intituladas como Over The Top (“OTTs”), bem como do aumento da aquisição de Smartphones e Smart TVs, além do aumento considerável no consumo do volume de dados, diante do advento do coronavírus (COVID-19), e das transformações tecnológicas sobrevindas da tecnologia 5G.

\section{OS SETORES DE TELECOMUNICAÇÕES E O SEAC}

\subsection{AS TELECOMUNICAÇÕES}

O desenvolvimento do setor das telecomunicações, no Brasil, foi acompanhado de importantes transformações constitucionais, legais e regulatórias, as quais permitiram as adaptações necessárias no ordenamento jurídico brasileiro com vistas ao desenvolvimento das telecomunicações ao longo das décadas do século XX, especialmente a partir da sua segunda metade. 
Neste contexto, vale destacar a estrutura da telefonia fixa originalmente existente no Brasil, em idos dos anos de 1960, quando havia uma gama de 1.200 (mil e duzentas) operadoras, todas prestadoras de serviços de telecomunicações, contudo sem qualquer coordenação entre si. A edição do Código Brasileiro de Telecomunicações ("CBT”), implementado pela Lei no. 4.117 de 1962, surgiu como uma resposta à falta de coordenação então diagnosticada. Criou-se, assim, o Sistema Brasileiro de Telecomunicações, com vistas à prestação desses serviços entre Estados, sob a coordenação da União ${ }^{6}$.

A criação do CBT não foi a única resposta à estrutura original das telecomunicações, no Brasil. Em 1965, também houve a criação da Empresa Brasileira de Telecomunicações ("Embratel"), incumbida de interligar todas as capitais e as principais cidades brasileiras. A Embratel também paulatinamente assumiu as ligações internacionais, à medida que expiravam as concessões anteriormente outorgadas.

Na década de 1970, notadamente por meio da Lei no. 5.792, de 11.07.1972, criou-se a Telecomunicações Brasileiras S.A. (“TELEBRAS"), sociedade holding incumbida da consolidação de várias sociedades que operavam a telefonia no país. Foi nesta época que as sociedades operadoras de telefonia foram reduzidas a uma por Estado da Federação.

Em seguida, a Embratel foi transformada em sociedade de economia mista, controlada pela TELEBRAS, e, em 1974, por meio do Decreto no. 74.379, a TELEBRAS foi designada como concessionária-geral para a exploração dos serviços de telecomunicações em todo o território nacional.

Este modelo dos serviços de telecomunicações como um serviço público, prestado por sociedades sob o controle do Estado, em que havia uma concessionária de serviços públicos por cada unidade da federação, controlada por uma sociedade holding, o chamado Sistema TELEBRAS, vigorou mesmo após o advento da Constituição Federal de 1988.

Evidenciou-se, no entanto, que o modelo dos serviços de telecomunicações, substancialmente como serviços público, demandaria do Estado constantes investimentos, os quais se majoravam exponencialmente diante das necessidades de construção de

\footnotetext{
6 “Até o advento do Código Brasileiro de Telecomunicações - CBT (Lei nº. 4.117/1962), o serviço de telefonia local era prestado por cerca de 1.200 operadoras, se qualquer tipo de coordenação, e o serviço de chamadas internacionais era oferecido por um pequeno número de empresas estrangeiras. Com a promulgação do CBT, foi criado o Sistema Nacional de Telecomunicações, para prestar serviços de telefonia entre Estados, que veio a interligar todas as capitais e as principais cidades do País, assumindo, ainda, paulatinamente, as ligações internacionais, à medida que expiravam as concessões anteriormente outorgadas." (ARAGÃO, Alexandre Santos de, 1969; Direito dos serviços públicos; 3a. ed; Rio de Janeiro; Forense; 2013; p. 257).
} 
infraestruturas reclamadas para o atendimento das demandas criadas pelas novas tecnologias. Esses aportes frequentes e crescentes tornaram o modelo de negócio, baseado numa acepção das telecomunicações como modalidade de serviço público, insustentável diante dos sabidos recursos escassos de que o Estado dispunha ${ }^{7}$.

Na década de 1990, sobrevieram diversas alterações no arcabouço jurídicoinstitucional brasileiro. Foram elas: (i) o advento da Emenda Constitucional n ${ }^{\circ} .8$, aos 08 de agosto de 1995 ("EC 8"), com vistas ao fim do monopólio estatal na prestação dos serviços de telecomunicações; (ii) a edição de nova Lei estruturante para o setor, a LGT, com a revisão do papel nele exercido pelo Estado; (iii) a criação de uma agência reguladora independente para o setor, a Anatel; (iv) a introdução de mecanismos com vistas à criação de competição no mercado após a sua privatização; (v) a redefinição de tarifas e extinção dos subsídios cruzados; e (vi) a cisão da TELEBRAS previamente ao processo de privatização ${ }^{8}$.

Estas mudanças substanciais, seguidas do advento da LGT, permitiram o ingresso de capital estrangeiro capaz de fazer frente aos investimentos de elevada monta que se faziam necessários para o desenvolvimento dos então revolucionários serviços de telefonia móvel, ou SMP, o que incluía o incremento da rede existente, além da criação de nova rede própria, com vistas ao desenvolvimento dessas atividades.

Esse arcabouço constitucional, legal e regulatório, editado nos anos 90 do século XX, foi essencial para o desenvolvimento do setor de telecomunicações no país, já naquela época altamente impactado pelo advento da telefonia móvel, e, portanto, dissociado da estrutura original da telefonia fixa, notadamente estruturada, no Brasil, em regime de serviços público.

\footnotetext{
7 "As transformações do setor de telecomunicações em todo o mundo decorreram de três principais fatores indissociavelmente ligados: I) globalização da economia; II) evolução tecnológica; e III) velocidade das mudanças no Mercado e nas necessidades dos consumidores, aliada à falta de recursos para novos investimentos. Economicamente, constata-se a passagem do modelo de exploração monopolista (até a década de 80), seja estatal (como era no Brasil) ou privado (situação encontrada nos Estados Unidos, a AT\&T, ainda que submetida a uma intense regulação) para um ambiente concorrencial." (ARAGÃO, Alexandre Santos de, 1969; Direito dos serviços públicos; 3a. ed; Rio de Janeiro; Forense; 2013; p. 257).

8 “Com a Emenda Constitucional n'. 8 , de 15 de agosto de 1995, que alterou a redação do art. 21, incisos XI e XII, $a$, da Constituição de 1988, deu-se o início da nova política d setor de telecomunicações. Da simples leitura desses dispositivos, evidenciam-se as alterações introduzidas no texto constitucional: $1^{\circ}$ ) supressão do monopólio estatal sobre os serviços de telecomunicações; $2^{\circ}$ ) uniformização do regime de exploração dos serviços de telecomunicações, agora concentrados no inciso XI; $3^{\circ}$ ) a exigência de uma lei sobre 'a organização dos serviços, a criação de um órgão regulador e outros aspectos institucionais '”. (GROTTI, Dinorá Adelaide Musetti; Regime Jurídico das Telecomunicações: Autorização, Permissão e Concessão; Revista interesse público; v.3; n.12; out./dez. 2001; p. 123).
} 


\subsection{O SEAC}

O histórico da televisão por assinatura ("TV por Assinatura") indica que o seu surgimento converge com a necessidade de se distribuir sinais de televisão aberta a pequenas comunidades que não os recebiam. A criação se deu nos anos 40 do século $\mathrm{XX}$, nos Estados Unidos, e, no Brasil, a TV por Assinatura ganhou força na década de 90 do mesmo século XX.

No Brasil, em dezembro de 1989, o governo federal introduziu oficialmente a TV por Assinatura. Já em 1991, grandes grupos de comunicação ingressaram no setor, mediante investimento e o emprego de novas tecnologias. Ainda nos anos 90 do século XX, foi promulgada a lei no 8.977, de 06 de janeiro de 1995 (a "Lei do Cabo"), por meio da qual as permissões a prestadores de serviços de TV por Assinatura foram transformadas em concessões, de modo que ainda foi decidido que novas licenças somente seriam outorgadas por meio de licitação.

Promulgada a LGT, a Anatel assumiu a função de regulador de todos os serviços de telecomunicações, inclusive de TV por Assinatura. A Anatel deu também continuidade aos processos licitatórios de expansão dos serviços de TV por Assinatura iniciados então pelo Ministério das Comunicações.

Em 1999, as sociedades vencedoras de processos licitatórios iniciaram a implantação de suas bases operacionais para, em 2000, iniciarem as suas operações no país. O mercado fluiu, assim, por um período de crescimento acelerado, seguido de outro caracterizado pelo ingresso de grupos de prestadoras de serviços de telefonia no segmento da TV por Assinatura, tanto mediante o ingresso daquelas nos quadros sociais de sociedades prestadoras de serviços de TV por Assinatura, quanto por meio da incorporação destas prestadoras pelas operadoras de telefonia.

Passada a primeira década dos anos 2000, em 2012, houve a promulgação da Lei do SeAC, cujo reconhecido objetivo era o de "... aumentar a produção e a circulação de conteúdo audiovisual brasileiro, diversificado e de qualidade, gerando emprego, renda, royalties, mais profissionalismo e o fortalecimento da cultura nacional"9.

\footnotetext{
${ }^{9}$ ANCINE. Agência Nacional do Cinema. Lei da TV paga. Disponível em <https://ancine.gov.br/ptbr/conteudo/lei-da-tv-paga >.
} 
A Lei do SeAC, que tramitou no Congresso Nacional por 5 (cinco) anos, tinha por propósito declarado a abertura do mercado a novos competidores, a ampliação da oferta, o estímulo à diminuição de preços finais aos assinantes, dentre outros objetivos. A lei igualmente se preocupou em restringir a propriedade cruzada entre os setores de telecomunicações e o de radiodifusão, além da segmentação da cadeia de valor do audiovisual, mediante a separação das atividades de produção e transmissão do conteúdo ao consumidor final.

A intenção manifestada pelo legislador, à época das discussões havidas no Congresso Nacional com vistas à aprovação do projeto de lei que se tornou a Lei do SeAC, era no sentido de que as prestadoras de serviços de telecomunicações teriam faturamentos muito maiores do que as sociedades produtoras do conteúdo que distribuiriam. A partir deste racional e como forma de se evitar distorções no mercado, buscou-se restrições na participação cruzada entre os setores de audiovisual e de telecomunicações.

Neste cenário, vale destacar que a Lei do SeAC também estabeleceu que as atividades de programação e empacotamento do conteúdo audiovisual estariam a cargo da regulação e fiscalização da Ancine, conforme dispõe o artigo $9^{\circ}$, parágrafo único, da lei, enquanto a distribuição do conteúdo sob a regulação e fiscalização da Anatel, conforme preceitua o artigo 29, parágrafo único, da mesma Lei do SeAC.

\section{A DEPENDÊNCIA DAS TELECOMUNICAÇÕES E DO SEAC ÀS ESTRUTURAS DE REDE}

O desenvolvimento de determinadas atividades econômicas pressupõe a existência de infraestruturas a ela indispensáveis. Isso acontece exemplificativamente na prestação de serviços de telecomunicações, sejam STFC, ou SMP, distribuição de energia elétrica, adução e distribuição de água, coleta de esgoto, transporte de gás canalizado, linhas de transporte ferroviários, rodovias, aeroportos.

A construção e manutenção dessas infraestruturas indispensáveis implicam em altos investimentos por parte dos atores que pretendem explorar as atividades delas dependentes, de maneira que os custos incorridos pelos agentes que pretendam explorá-las, tanto para fins de sua construção, como manutenção e incremento, são sempre elevados. 
Os custos altos relacionados às redes de infraestruturas essenciais para a exploração de determinadas atividades econômicas influenciam a que esses mercados se organizem em formato de monopólio natural, eis que a duplicação dessas redes não se justifica sob uma perspectiva econômica. Isto porque os custos fixos de produção são exageradamente altos, quando comparados aos custos variáveis, motivados pela existência de redes de infraestrutura de grandes proporções, essenciais à prestação de determinadas atividades.

Nos setores que dependem de estruturas de rede, tais quais as telecomunicações e o SeAC, a vantagem econômica dos seus atores decorre da economia de grande escala praticada pelo detentor das infraestruturas, i.e., quanto maior a produção por um único agente menor será o custo total dividido pelo número de unidades produzidas, ou o custo unitário médio do produto. O ganho de escala associado à inviabilidade econômica na duplicação da infraestrutura de rede impossibilita a prestação de determinadas atividades em regime de concorrência. Isto porque os custos fixos elevados para potenciais concorrentes, coincidentes com os custos de duplicação de infraestruturas materiais já existentes, desestimulam qualquer iniciativa racional no sentido de competição com o monopolista.

A perspectiva econômica indica que nos mercados dependentes de infraestruturas de rede, o regime de livre concorrência implicaria em acréscimo de custo impraticável para o ingresso de novos atores, à medida que necessariamente teriam de instalar infraestruturas paralelas para competirem com os líderes estabelecidos.

No entanto, a experiência do setor de telecomunicações, especialmente a prestação de serviços STFC e SMP, concomitantemente em regimes público e privado, indicaram que, mesmo que umbilicalmente dependentes de infraestruturas de rede, a exploração dessas atividades permitiu cenários de livre concorrência, sobrevindo de um modelo competitivo, caracterizado pela pluralidade de atores competidores.

Há, também, no SeAC uma pluralidade de prestadores de serviços de TV por Assinatura, os quais, com as suas infraestruturas de redes próprias, competem por clientes no mercado de distribuição do conteúdo audiovisual produzido por outros atores. Os avanços tecnológicos sobrevindos nas telecomunicações e no SeAC propiciam soluções práticas com vistas à viabilização da competição. A tecnologia assume papel de protagonismo porque permite o aproveitamento de uma mesma infraestrutura, ou rede, integral, ou parcialmente, por duas prestadoras concorrentes. Confere-se o direito de acesso às infraestruturas estabelecidas no setor por parte de concorrentes, desde que preenchidos certos requisitos. 
A tecnologia permite a utilização de uma mesma infraestrutura, ainda que parcialmente, como base para um sistema concorrencial. É exatamente o que se percebe em acordos e modelos de negócio adotados no setor de telecomunicações, energia elétrica, estes mencionados a título exemplificativo.

\subsection{A DOUTRINA DAS ESSENTIAL FACILITIES}

Utilizada com maior intensidade na Europa Ocidental e nos Estados Unidos, a doutrina das essential facilities se estrutura a partir da identificação de que o desempenho de certas atividades econômicas pressupõe a existência de determinadas infraestruturas. Essas infraestruturas são essenciais e estão habitualmente presentes nos serviços prestados em rede, como se caracterizam o SeAC e o setor das telecomunicações.

A construção e a manutenção dessas infraestruturas demandam desembolsos volumosos por parte de seus titulares e, na prática, tornam impossíveis as duplicações dessas infraestruturas. A solução encontrada, na experiência estrangeira, para o enfrentamento dessas dificuldades consiste no compartilhamento compulsório de infraestruturas indispensáveis, tidas como o núcleo das essential facilities. A alternativa constrange os titulares da propriedade, ou de direitos de uso de uma determinada infraestrutura indispensável à determinada atividade econômica, ao compartilhamento da sua utilização com outros competidores, respeitados determinados limites e observadas certas condições.

Neste contexto, o titular de posição dominante em determinado mercado é constrangido a ceder a potenciais competidores vantagens que permitem a instauração de um modelo competitivo.

\section{DESAFIOS DO SETOR DE TELECOMUNICAÇÕES}

As telecomunicações são altamente influenciadas pelo advento de novas tecnologias, substancialmente disruptivas dos modelos e estruturas de negócio implementados no setor. Conforme revela o próprio histórico das telecomunicações, se é verdade que elas são impactadas pelos avanços na tecnologia, também é certo que os atores tradicionais do setor são altamente resilientes, o que se depreende dos diversos papéis e contornos que as atividades por eles desempenhadas assumiram ao longo do tempo. 
O fenômeno da rede mundial de computadores e todas as transformações dele decorrentes, dentre as quais exemplificativamente o surgimento recente da intitulada internet das coisas, fizeram com que os prestadores de serviços de telecomunicações se pusessem diante de um novo ciclo de transformações profundas, que encerram desde a presença de novos atores nesse mercado à existência de novas estruturas e modelos de negócios.

As transformações implementadas por meio da distribuição das mais variadas espécies de conteúdo, diretamente na internet, levada a cabo pelas chamadas OTTs, implicaram na distribuição direta, por meio da rede mundial de computadores, de conteúdos providos de maneira cada vez mais descentralizada e pulverizada, seja por meio de Smartphones, ou de Smart Tvs. Esse é um bom exemplo das demandas enfrentadas pelos prestadores de serviços de telecomunicações, que se veem obrigados a um reposicionamento estratégico no mercado.

Soma-se a este cenário de intensas transformações a recente disseminação da doença COVID-19 em âmbito mundial e igualmente no todo território nacional. A doença acelerou um ciclo de mudanças comportamentais da sociedade, e que não é exatamente objeto deste estudo, influenciado pelas medidas adotadas como forma de se evitar a propagação acelerada da doença. Desta forma, a demanda abrupta e intensa por alternativas remotas de formas de trabalho e meios produção, com a consequente intensificação no consumo e tráfego de dados, traz desafios ainda mais intensos às prestadoras de serviços de telecomunicações.

O cenário reclama por mudança em relação à estrutura pensada na década de 1990 para o setor de telecomunicações, quando as demandas eram substancialmente baseadas no tráfego de voz. Atualmente, esse tráfego de voz deu lugar a um cada vez mais elevado e frequente consumo e tráfego de dados. Este fluxo de dados, por parte de usuários e clientes, é cada vez maior. No entanto, os dados trafegam pelas mesmas redes que atendiam às estruturas de telecomunicações fundadas no conceito de voz.

Os atores do setor de telecomunicações, por sua vez, esforçaram-se e continuam a se dedicar para o atendimento de demandas sempre crescentes a eles apresentados, com vistas ao incremento das capacidades de suas redes de telecomunicações, o que reclama por investimentos de grande monta em infraestrutura. Ao mesmo passo, as suas margens de lucro desses são cada vez mais pressionadas, o que faz com que as prestadoras revisitem os seus modelos de negócios e tenham de tomar decisões entre (a) focarem nas suas atividades principais, consubstanciadas no provimento de serviços de telecomunicações; ou (b) posicionarem-se como provedoras de conteúdo aos seus clientes, tomada de decisão mais 
voltada ao incremento do portfólio do produtos e serviços que ofertam; ou (c) estruturarem as suas atividades não exclusivamente no provimento de serviços de telecomunicações, mas no provimento de infraestruturas e meios de rede capazes de atender às demandas de novos atores que ingressaram e ingressarão no mercado, seja para o provimento de conteúdo, ou de produtos e serviços.

Além do dilema da tomada de decisão por parte das prestadoras de serviços de telecomunicações, especialmente em relação ao posicionamento que devem seguir diante de um mercado caracterizado pela sua constante mutação e evolução, o setor foi incrementado pela entrada de novos atores que, nos idos de 1990, nele não figuravam. Exemplo desses novos atores são os detentores de equipamentos, infraestruturas e meios de rede, como as chamadas tower companies, ou torreiras, além das sociedades provedoras de equipamentos e tecnologia que viabilizam a estruturação das redes de telecomunicações.

A assimetria regulatória gerada pelo ingresso desses novos atores é gritante, à medida que eles não estão submetidos aos mesmos compromissos de qualidade e de universalidade impostos, pela Anatel, às prestadoras de serviços de telecomunicações. No entanto, pressionam de sobremaneira as margens de lucro cada vez mais reduzidas das prestadoras de serviços de telefonia, à medida que impõem custos consideráveis atrelados aos investimentos reclamados e necessários em infraestrutura, os quais são arcados pelos atores tradicionais do mercado. Os novos atores, assim, incrementam os custos de transação de uma cadeia de produção já caracterizada pela sua considerável complexidade.

Vale dizer que à exceção do consumo de dados, este sim cada vez mais crescente, percebe-se que o consumo de voz é cada vez menor no setor de telecomunicações, ao passo que o acirramento pela fidelização de clientes se tornou um dos principais enfoques das prestadoras desses serviços, especialmente diante do grau de saturação do modelo de negócio pensado para o mercado.

O setor de telecomunicações está diante de severas transformações, especialmente quando comparado à concepção dele havida nos anos de 1990. O reposicionamento de prestadores tradicionais do mercado, a entrada de novos atores, a necessidade de otimização de investimentos com vistas ao desenvolvimento de novas tecnologias, o consumo e o tráfego maior de dados, são alguns dos fenômenos percebidos no cenário de latentes transformações.

Cabe aos tradicionais atores do setor de telecomunicações otimizarem os seus custos, como se dá por meio do advento do compartilhamento de infraestruturas de rede e meios de 
rede. Esses atores passaram a modular os seus negócios com vistas à eficiência dos seus custos e investimentos. Neste cenário, os acordos de compartilhamento de redes e meios de rede representam uma alternativa a essas sociedades, asfixiadas pelas demandas crescentes de provimento de redes maiores e com maior capacidade de absorção do tráfego de dados brutalmente crescente de seus clientes.

A procura pela eficiência nos gastos permitirá às prestadoras de serviços de telecomunicações direcionarem os seus esforços não exclusivamente às suas redes e infraestruturas de rede, que reclamam por investimentos substanciais, mas permitirá que também destinem recursos para soluções que propiciem a prestação de serviços de qualidade e inovadores.

\subsection{O COMPARTILHAMENTO DE INFRAESTRUTURAS DE REDE NO SETOR DE TELECOMUNICAÇÕES}

As soluções de compartilhamento podem ser implementadas em níveis diferentes no âmbito das redes utilizadas pelas prestadoras de serviços de telecomunicações. A classificação pode advir da solução técnica utilizada com vistas ao compartilhamento, o que reflete graus e formas diferentes em que as estruturas das redes são compartilhadas.

O compartilhamento pode acontecer no âmbito das torres empregadas nas redes de telecomunicações, inclusive as torres utilizadas na arquitetura da rede elétrica, mediante a instalação de pontos de fixação que atendem às redes de telecomunicações e encerram desde o compartilhamento de espaços nestas estruturas, inclusive o das estruturas de apoio de torres, os cabinets, como também incluem a divisão de custos de manutenção dessas infraestruturas.

A solução pode também acontecer no âmbito dos equipamentos instalados nas chamadas estações rádio-base ("ERBs") que atendem às redes de telecomunicações, quais sejam as antenas instaladas pelas prestadoras de serviços de telecomunicações, implementados por meio de acordos intitulados como de compartilhamento, ou RAN-Sharing.

O compartilhamento pode também ser implementado no âmbito das soluções de controle dessas redes de telecomunicações, relativamente às centrais de comutação das radiofrequências mediante as quais os clientes de prestadores são interligados, além das centrais responsáveis pela interligação com outras centrais e a formação das redes de centrais. 
A implementação do compartilhamento pode se dar no âmbito dos elementos dessas redes de telecomunicações, resultado de soluções técnicas que variam em gradação à medida que os equipamentos compartilhados podem ser aqueles componentes das redes básicas utilizadas para a prestação desses serviços, ou as chamadas rede Backbone, bem como os equipamentos componentes das redes Backhaul, ou redes de acesso. A solução pode também ocorrer mediante a outorga de uso de rádio frequências, as quais são outorgadas primariamente aos prestadores de serviços de telecomunicações, pelo Estado. Neste cenário, o outorgante (o Estado) permite a afetação do uso de sua capacidade ociosa, em caráter secundário, a prestadoras de serviços de telecomunicações concorrentes.

Por fim, é também possível o compartilhamento por meio de acordos nacionais de roaming, os quais refletem situações em que prestadoras de serviços de telecomunicações não propriamente compartilham as suas redes, ou meios de rede, mas simplesmente usam as redes uma das outras para o provimento dos serviços de telecomunicações aos seus próprios clientes.

Os exemplos de estruturas de compartilhamento descritos anteriormente não se presumem como os únicos utilizados pelas prestadoras de serviços de telecomunicações. Dessa forma, é amplamente viável e admissível que haja, ou haverá, outras soluções técnicas capazes da oportunizar a implementação de novas estruturas de compartilhamento por parte desses atores.

\section{AS TRANSFORMAÇÕES PELAS QUAIS PASSA O SEAC}

As atividades dos prestadores de serviços de TV por Assinatura, notadamente de distribuição do conteúdo audiovisual aos consumidores finais sujeitas à Lei do SeAC, também prescindem de infraestruturas de rede, essenciais à viabilização da prestação desses serviços. As redes, no entanto, não são compartilhadas por competidores do mercado. Não há na Lei do SeAC uma disciplina própria ao compartilhamento de infraestrutura, além do uso compartilhado de postes de luz, mediante a utilização de pontos neles instalados para a fixação das redes que atendem à distribuição do conteúdo provido pelo SeAC.

A conclusão gerada é a de que muito embora houvesse manifesta preocupação do legislador, à época da debates com vistas à promulgação da Lei do SeAC, no sentido de incentivar o ingresso de novos atores e em prol da concorrência naquele segmento, o marco 
regulatório não se debruçou sob a possibilidade de viabilização do ingresso de concorrentes no mercado por meio do compartilhamento de infraestruturas de rede pertencentes aos prestadores nele já presentes, quais sejam os atores tradicionais.

O mercado da TV por Assinatura é também marcado pelos altos investimentos empregados pelos prestadores dos serviços de distribuição do conteúdo audiovisual, tanto na construção como na manutenção das infraestruturas de rede necessárias ao exercício dessas atividades. Esses investimentos representavam, na prática, barreiras ao ingresso de potenciais novos atores entrantes no setor, à medida que não se ventila a possibilidade de compartilhamento de infraestruturas entre concorrentes.

As infraestruturas de rede se de um lado representam diferencial competitivo aos seus titulares, de outro basicamente refletem uma barreira de entrada a novos atores no setor. No entanto, essas infraestruturas deixaram de ser imprescindíveis à distribuição do conteúdo audiovisual com o advento das OTTs de vídeo, do aumento da aquisição de Smartphones e Smart TVs, dos avanços tecnológicos, todos no sentido de permitirem o streaming de vídeos por meio da internet.

$\mathrm{O}$ advento das novas tecnologias resultou na quebra das barreiras de entrada a novos concorrentes, conforme havia no segmento da TV por Assinatura, de maneira que atualmente um volume maior de conteúdo é acessado diretamente por parte dos consumidores finais diretamente em plataformas digitais existentes na internet e em aplicativos instalados em Smartphones e Smart TVs, sem que haja a necessidade de contratação dos serviços ofertados pelos atores inicialmente compreendidos como essenciais na estrutura concebida pelo SeAC, quais sejam as prestadoras de serviços de TV por Assinatura. Portanto, é latente a redução de clientes e assinantes dos serviços de TV por Assinatura, provido por prestadores de serviços do SeAC, enquanto cresce o consumo de conteúdo audiovisual diretamente por meio de plataformas e aplicações de internet ${ }^{10}$.

\footnotetext{
10 "Apesar de novamente ter havido encolhimento na base de assinantes da TV paga, a queda de $3 \%$ foi um pouco menor do que a do ano anterior, de 3,6\%. Segundo dados da Anatel, o ano de 2018 fechou com 17,6 milhões de assinantes, uma perda de 550 mil em comparação com dezembro de 2017. A partir de estudos anteriores do Obitel, é possível conjecturar que a concorrência com serviços OTT e a atual queda de poder aquisitivo da população são os fatores mais importantes no processo. Em termos de tecnologia, segue majoritário no país o serviço por satélite (DTH), que detém $54 \%$ do mercado, seguido pelo cabo, com $42 \%$. Vale ressaltar que cresce a tecnologia da fibra ótica, agora com $4 \%$ do mercado. Os canais de espaço qualificado ainda superam as exigências da Lei do SeAC (Lei no 12.485/2011), principalmente na exibição de conteúdo brasileiro independente. Os grupos midiáticos Globo e Fox foram os que mais se destacaram na veiculação de obras brasileiras, inclusive independentes.”. (LOPES, Maria Immacolata Vassalo de; LEMOS, Ligia Prezia. BRASIL: streaming, tudo junto e misturado. In: Modelos de distribuição da televisão por internet: atores, tecnologias,
} 
As transformações promovidas pelo advento de novas tecnologias fizeram com que os prestadores de TV por Assinatura percebessem quedas substanciais nos volumes e número de clientes, fenômeno este também incentivado pela mudança comportamental das novas gerações. As novas gerações estão mais habituadas ao acesso e consumo de conteúdos nãolineares, por meio do acesso a plataformas de Videos On Demand ("VoD”), ou de OTTs, que oferecem o conteúdo diretamente aos consumidores finais sem quaisquer etapas intermediárias, ou gradeamento de programação ${ }^{11}$.

As cadeias de atividades das OTTs não incluem custos semelhantes aos incorridos pelos prestadores de serviços de TV por Assinatura, notadamente com a construção e manutenção de infraestruturas de rede. Esta peculiaridade permite às OTTs um diferencial concorrencial à medida que praticam preços bem mais agressivos em relação às ofertas apresentadas no mercado da TV por Assinatura. Este cenário leva a prognósticos não muito otimistas para o futuro de prestadores do $\mathrm{SeAC}^{12}$.

\section{A ABORDAGEM DAS AGÊNCIAS REGULADORAS EM RELAÇÃO AO COMPARTILHAMENTO}

estratégias. org. Maria Immacolata Vassallo de Lopes e Guillermo Orozco Gómez. Porto Alegre: Sulina, 2019, p.78).

11 "O acesso dos brasileiros à internet segue em ascensão, como temos apontado nos últimos anuários. De acordo com o IBGE, a conexão via celular é a preferida de $94,6 \%$ dos usuários, e a pesquisa ainda aponta que $76,4 \%$ desses acessos foram realizados para assistir a vídeos, programas, séries e filmes. O país está em quarto lugar no ranking mundial de usuários de internet, atrás apenas de EUA, Índia e China, respectivamente. Devido a esse crescente e constante aumento da assistência de vídeos e séries em plataformas on-line, os serviços on demand se consolidam no Brasil. A Netflix é o mais popular, com 18\% do mercado, seguida de Globoplay, com 4\%, e Telecine Play e Sky Online, com 3\% cada." (LOPES, Maria Immacolata Vassalo de; LEMOS, Ligia Prezia. BRASIL: streaming, tudo junto e misturado. In: Modelos de distribuição da televisão por internet: atores, tecnologias, estratégias. org. Maria Immacolata Vassallo de Lopes e Guillermo Orozco Gómez. Porto Alegre: Sulina, 2019, p. 81/82).

12 "Quase uma década após a implantação no país, a televisão distribuída por internet segue demandando novos formatos de conteúdo e modelos de negócios, além de adequação de contexto. São novas configurações quanto a 'território, mercado, nação e área de sinal' (Lobato, 2019: 15), que incidem sobre estruturas rígidas; são padrões que se apropriam e demandam novas percepções para as dinâmicas vigentes. Isso posto, entendemos que os participantes desse jogo de demandas integram uma 'economia da atenção, na qual o olhar é uma das mercadorias mais cobiçadas"”. (LOPES, Maria Immacolata Vassalo de; LEMOS, Ligia Prezia. BRASIL: streaming, tudo junto e misturado. In: Modelos de distribuição da televisão por internet: atores, tecnologias, estratégias. org. Maria Immacolata Vassallo de Lopes e Guillermo Orozco Gómez. Porto Alegre: Sulina, 2019, p. 105). 
A LGT, no seu artigo $73^{13}$, cria um direito às prestadoras de serviços de telecomunicações de interesse coletivo de utilizarem postes, dutos, condutos e servidões pertencentes, ou controladas, por outras prestadoras de serviço de telecomunicações, ou de outros serviços de interesse público, de maneira não discriminatória e a preços e condições justas e razoáveis.

No mesmo sentido da LGT, a Lei $\mathrm{n}^{\circ} 11.934$ de 2009, ao regulamentar as ondas não ionizantes e tratar dos limites da exposição humana a campos elétricos, magnéticos e eletromagnéticos, estabelece uma obrigatoriedade de compartilhamento das torres utilizadas pelas prestadoras de serviços de telecomunicações, que utilizarem estações transmissoras de radiocomunicação, quando se encontrem afastadas em espaçamento inferior a 500 (quinhentos) metros ${ }^{14}$. A Lei 13.116 de 2015, que estabelece normas gerais para implantação e compartilhamento da infraestrutura de telecomunicações (a "Lei das Antenas"), no seu artigo $14{ }^{15}$ também estabelece a obrigação do compartilhamento da capacidade excedente da infraestrutura de suporte, exceto quando houver justificado motivo técnico.

Em se tratando da Lei do SeAC, não há um dispositivo específico que verse sobre o compartilhamento de infraestruturas das redes essenciais à prestação dos serviços de TV por Assinatura.

O compartilhamento de infraestruturas é objeto de análises por parte da Anatel e da Agência Nacional de Energia Elétrica (“Aneel”). Neste sentido, vale destacar esforço das agências para a implementação da Resolução Conjunta Anatel e Aneel n 4/2014 ("Resolução Conjunta $n^{\circ} 4 / 2014$ ") ${ }^{16}$. As iniciativas recentes dessas agências envolvem desde a tomada de subsídios sobre o compartilhamento de postes, à realização de uma Análise de Impacto

\footnotetext{
${ }^{13} \mathrm{O}$ artigo 73 da lei $\mathrm{n}^{\circ} 9.472$ de 1997 dispõe que "As prestadoras de serviços de telecomunicações de interesse coletivo terão direito à utilização de postes, dutos, condutos e servidões pertencentes ou controlados por prestadora de serviços de telecomunicações ou de outros serviços de interesse público, de forma não discriminatória e a preços e condições justos e razoáveis."

${ }^{14} \mathrm{O}$ artigo 10 da Lei ${ }^{\circ} 11.934$ de 2009 dispõe que "É obrigatório o compartilhamento de torres pelas prestadoras de serviços de telecomunicações que utilizam estações transmissoras de radiocomunicação, conforme definição constante do art. 73 da Lei $\mathrm{n}^{\circ}$ 9.472, de 16 de julho de 1997, nas situações em que o afastamento entre elas for menor do que 500 (quinhentos) metros, exceto quando houver justificado motivo técnico."

${ }^{15} \mathrm{O}$ artigo 14. da Lei $\mathrm{n}^{\mathrm{o}} 13.116$ de 2015 dispõe que "É obrigatório o compartilhamento da capacidade excedente da infraestrutura de suporte, exceto quando houver justificado motivo técnico."

${ }^{16}$ Resolução Conjunta $n^{\circ}$ 4, de 16 de dezembro de 2014 (Aneel e Anatel). Aprova o preço de referência para o compartilhamento de postes ente distribuidoras de energia elétrica e prestadoras de serviços de telecomunicação, a ser utilizado nos processos de resolução de conflitos, e estabelece regras para uso e ocupação dos Pontos de Fixação.
} 
Regulatório (“AIR”) sobre a temática dos ponto de fixação instalados em postes empregados na rede de energia elétrica, além da atualização da Resolução Conjunta nº 4/2014.

A Anatel está atenta ao compartilhamento de postes, especialmente motivada pela iminente chegada da tecnologia 5G, no Brasil. A agência associa a demanda intensa pelo incremento de redes, por parte de prestadores de serviços de telecomunicações, à crescente e desordenada ocupação de postes de luz por parte desses atores, com vistas à instalação de pontos de fixação necessários à construção das suas redes de telecomunicações.

Conforme dados coletados no sítio da Anatel, dos 46 (quarenta e seis) milhões de postes de energia elétrica instalados no país, 9 (nove) milhões estão em situação de maior urgência e reclamam pela readequação de seus usos, notadamente porque possuem fiação de quatro ou mais prestadores de serviços de telecomunicações. A agência indica que em muitas regiões há pluralidade de sociedades prestadoras se serviços de telecomunicações que disputam espaços nessas infraestruturas. Também conforme sinaliza a agência, os estados que apresentariam maior situação de criticidade em relação a infraestruturas sobrecarregadas seriam São Paulo, com 3 (três) milhões de postes em situação de urgência, Minas Gerais, com 1 (um) milhão de postes em situação de urgência, Paraná, com 1 (um) milhão de postes em situação de urgência, Rio de Janeiro, com 800 (oitocentos) mil de postes em situação de urgência; e Rio Grande do Sul, com 600 (seiscentos) mil de postes em situação de urgência. Em conformidade com estimativas da agência, as futuras antenas (small cells) da tecnologia o $5 \mathrm{G}$ possivelmente aumentariam a ocupação desses postes ${ }^{17}$.

Como justificativa para a revisão das regras de compartilhamento de postes, as agências apresentaram números que indicam a saturação das infraestruturas atualmente compartilhadas. Neste sentido, a Aneel indicou a existência de uma demanda de 40 (quarenta) milhões de acessos na telefonia fixa, 18 (dezoito) milhões de acessos de TV por Assinatura, 5 (cinco) mil operadoras de Serviço de Comunicação Multimídia e 31 (trinta e um) milhões de acessos de banda larga fixa no país ${ }^{18}$.

\section{CONCLUSÃO}

\footnotetext{
${ }^{17}$ Disponível em <https://www.anatel.gov.br/institucional/component/content/article/46-noticias/2076-anatel-eaneel-realizam-coletiva-sobre-compartilhamento-de-postes $>$

${ }^{18}$ Disponível em <https://www.anatel.gov.br/institucional/component/content/article/46-noticias/2080-anatel-eaneel-recebem-sugestoes-sobre-compartilhamento-de-postes>
} 
Nos últimos anos, tanto os setores das telecomunicações quanto o SeAC se viram em sensíveis transformações. Os fenômenos sobrevindos do advento das novas tecnologias são diversos. Exemplificativamente, pode-se nomear o surgimento das OTTs, o streaming de vídeo por meio da internet, o aumento no consumo de Smartphones e Smart TVs.

Somam-se a estes fenômenos as mudanças comportamentais de novas gerações, além do ingresso de novos atores nesses mercados (como os provedores dos equipamentos e soluções que atendem às redes de telecomunicações, além dos provedores de infraestruturas de rede como as torreiras), além das transformações aguardadas em relação à tecnologia 5G, e mais recentemente o advento da doença COVID-19 e os reflexos dela sobrevindos.

Os provedores de serviços de telecomunicações buscam alternativas capazes de tornar mais eficientes a destinação dos recursos empregados na construção e na manutenção das infraestruturas de rede essenciais à execução das atividades a que estão habituados. Eles se movem no sentido de otimizar e compartilhar as infraestruturas de que são titulares, especialmente diante da pressão sofrida e que resultam em margens de lucro cada vez menores, além da demanda pelo incremento nos investimentos em redes capazes de atender ao fluxo crescente do volume de dados gerados por aplicativos e plataformas acessadas pelos seus clientes.

As alternativas encontradas pelos prestadores de serviços de telecomunicações envolvem desde (a) a afetação do uso da capacidade ociosa de radiofrequências, em caráter secundário, não exploradas pelos titulares de direitos de uso em caráter primário; (b) os acordos de compartilhamento de infraestruturas ("RAN Sharing"), como forma de permitir o cumprimento de compromissos de abrangência imputados pela Anatel; (c) os acordos celebrados com os chamados mobile virtual network operators ("MVNOs"), estes consistentes em prestadores de serviços de telefonia celular que não possuem redes próprias, tampouco são titulares de radiofrequências, à medida que se emprestam de redes e infraestruturas de rede dos atores tradicionais do mercado.

Ainda no cenário mais recente, identificam-se alguns movimentos por parte de prestadoras de serviços de telecomunicações no sentido de compartilharem as suas infraestruturas de rede. Este movimento pode indicar uma tendência no setor das telecomunicações no sentido da renúncia, por parte de atores tradicionais do mercado, do diferencial competitivo que detém e lhes são conferidos pelas infraestruturas das redes que possuem, em prol da otimização de investimentos e alocação de recursos em serviços e 
soluções associadas às relações estabelecidas frente aos seus clientes. Isso sem descartar as discussões relativas ao reposicionamento estratégico por parte de atores do setor.

Não se evidenciam movimentos semelhantes no SeAC. Se por um lado é inegável que o segmento da TV por Assinatura enfrenta transformações estruturais, especialmente em razão do provimento de conteúdo audiovisual em volumes cada vez maiores por meio da internet, motivados especialmente pela OTTs de vídeo, pelo crescimento no consumo de Smartphones e Smart TVs, de outro lado os atores desse mercado não apontam para movimentos semelhantes aos identificado no setor de telecomunicações relativamente ao compartilhamento de infraestruturas de rede.

As infraestruturas, embora em primeiro momento representem barreiras à entrada de concorrentes no setor, podem se revestir de potencial solução para as prestadoras de serviços de TV por Assinatura. Essas infraestruturas - embora não sejam mais indispensáveis diante do advento das OTTs de vídeo, além de aplicativos e plataformas das mais variadas, bem como do streaming de vídeo na internet -, constituem alternativa relevante à distribuição do conteúdo audiovisual aos consumidores finais.

O compartilhamento se traduziria como uma alternativa a essas sociedades, as quais se veem pressionadas a revisitarem os seus modelos de negócios, de maneira que não podem descartar como potencial solução o cenário em que se posicionariam como provedoras de meios de rede, ou infraestruturas de rede, a outros atores, estes provedores do conteúdo que é destinado aos consumidores finais.

\section{REFERÊNCIAS}

ARAGÃO, Alexandre Santos de. "Direito dos Serviços Públicos"; 3a. Edição Revisada e atualizada; Forense; Rio de Janeiro; 2013.

CÂMARA, Jacintho Arruda. "Autorizações Administrativas vinculadas: o exemplo do setor de telecomunicações" in "Direito Administrativo e seus novos paradigmas" Alexandre Santos de Aragão e Floriano de Azevedo Marques Neto (Coordenadores); 1a. Edição; Belo Horizonte; Fórum; 2008.

GABATHULER, David. "Network sharing in 3rd generation mobile telecommunications systems: minding the coverage gap and complying with EC competition rules". Competition Policy Newsletter; number 3; Autumn 2003. 
GROTTI, Dinorá Adelaide Musetti; "Regime Jurídico das Telecomunicações: Autorização, Permissão e Concessão"; Revista interesse público. v.3, n.12, out./dez. 2001

LOPES, Maria Immacolata Vassalo de; LEMOS, Ligia Prezia. "BRASIL: streaming, tudo junto e misturado". In: "Modelos de distribuição da televisão por internet: atores, tecnologias, estratégias" (org. Maria Immacolata Vassallo de Lopes e Guillermo Orozco Gómez). Porto Alegre: Sulina, 2019.

MARQUES Neto, Floriano de Azevedo. "Concessões"; 1a. Edição; Belo Horizonte; Fórum; 2016.

MARQUES Neto, Floriano de Azevedo. "Bens públicos: função social e exploração econômica: o regime jurídico das utilidades públicas"; 1a. Edição; Belo Horizonte; Fórum; 2009.

MARQUES Neto, Floriano de Azevedo. "Direito das Telecomunicações e ANATEL"; in "Direito Administrativo Econômico"; Carlos Ari Sundfeld (Coordenador); 1a. Edição; 2a. tiragem; São Paulo; Malheiros; 2002.

MARQUES Neto, Floriano de Azevedo. "Regulação Estatal e Interesses Públicos"; 1 a. Edição; São Paulo; Malheiros; 2002.

MOREIRA Neto, Diogo de Figueiredo, "Poder, direito e Estado: o direito administrativo em tempos de globalização - in memoriam de Marcos Juruena Villela Souto/Diogo de Figueiredo Moreira Neto"; 1a. Edição; Belo Horizonte; Fórum; 2011.

NESTER, Alexandre Wagner. "Regulação e concorrência (compartilhamento de infraestruturas e redes)"; São Paulo; Dialética; 2006.

RAGAZZO, Carlos; VELOSO, Isabel Cristina. "Regulação e novas tecnologias: verticalização das OTTs de Vídeo". Revista da Faculdade de Direito da UFRGS; Porto Alegre; n. 37; p. 200-218; dez. 2017. 